\title{
LA PROFETISA JULdÁ Y LA PALABRA DE YHWH (2 R 22,11-20)
}

The Prophetess Huldah and the Word of Yhwh

Bernardeth Carmen Caero Bustillos *

RESUMEN: El artículo tiene como base el personaje de la profetisa Juldá (2 R 22,11-20). De ella se tienen pocos datos biográficos, aquellos de los que se disponen dan pautas sobre su importancia profética en un momento crucial por la que atravesaba Judá. En el texto sobresale la autoridad que ella ejercía como portavoz de YHWH. A parte de Juldá, los textos bíblicos mencionan a otras mujeres en la historia de la salvación. Las recensiones que se hacen de ellas tienden a darles un rol segundario en escenarios androcéntricos. El papel que tiene la mujer dentro de la teología tiene rasgos proféticos. Para emprender un camino sinodal, en el cual sea posible la plena participación de la mujer en la sociedad y en la Iglesia, será importante a parte de conocer sus frutos teológicos, conocer también los escenarios en los cuales ellas han escrito y estado presente con su voz.

PALABRAS CLAVE: Profetismo. Juldá. Sinodalidad.

ABSTRACT: The article is based on the character of the prophetess Huldah (2 Kings 22:11-20). There is little biographical information about her, but that which is available gives some indication of her prophetic importance at a crucial moment in Judah's history. Her authority as YHWH's spokesperson stands out in the text. Apart from Huldah, the biblical texts mention other women in salvation history, generally giving them secondary roles in androcentric settings. The role of women in theology has prophetic features. In order to embark on a synodal journey, in which the full participation of women in society and in the Church is possible, it will be important not only to know their theological fruits, but also to know the scenarios in which they have written and been present with their voice.

KEYWORDS: Prophethood. Huldah. Synodality.

* Universidad Católica Boliviana San Pablo, Cochabamba, Bolivia. 


\section{Introducción}

A 1 recibir la invitación para escribir un artículo sobre el tema "Mujer Ay Teología" la primera imagen que vino a mi mente fue el personaje de Juldá, puesto que el hacer teológico también está relacionado con una actitud profética. En el caso de las mujeres que hicieron y hacen teología juegan un papel importante los escenarios en las que ellas vivieron y en las que ellas entretejieron su caminar teológico.

¿Por qué escoger a la figura de Juldá? Si bien, los datos biográficos que tenemos de ella son pocos, estos se centran en el servicio que ella ejercía como profetisa (2 R 22,11-20). A partir de ese dato surgen las siguientes preguntas: ¿Qué elementos más se pueden leer entre las líneas del texto? ¿Cuáles son las características de su profecía? ¿Qué es lo que la relaciona con otras mujeres en el Primer Testamento, que ejercían una función parecida? ¿Qué aspectos innovadores podemos sacar de la lectura de $2 \mathrm{R}$ 22,11-20 para una propuesta de un camino sinodal? Para poder responder esas interrogantes comenzamos conociendo a Juldá.

\section{La profetisa Juldá}

Esporádicamente relatan los textos del Primer Testamento sobre mujeres con un papel religioso relevante (RAMOS, 2001, p. 35). Uno de esos personajes que llama la atención en el Antiguo Testamento es sin duda Juldá, cuyo nombre en hebreo חִ חלְ̦ (huldāh) pudiera significar "topo" (GRADL, 2012, p. 457) o "comadreja" (CALDUCH-BENAGES, 2008, p. 17). Siguiendo a Müller se tiene también otra alternativa de traducir dicho nombre, teniendo

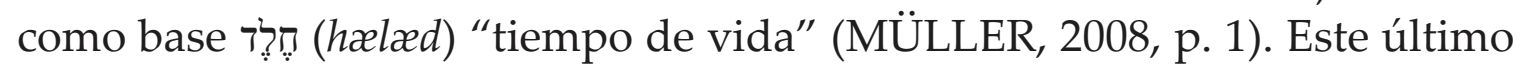
significado lo retomaremos posteriormente.

El nombre de Juldá aparece en dos textos del Antiguo Testamento (2 R 22,11-20; 2 Cr 34,22-28). En el Texto de 2 R 22,14 se indican algunos rasgos biográficos de la profetisa: ella es mujer de Salún - hijo de Ticvá, quien era hijo de Jarjás - él estaba encargado del vestuario. También se menciona el lugar donde ella vivía, que era el Barrio Nuevo de Jerusalén.

A diferencia del libro de Reyes, en el libro de Crónicas se menciona el rollo en relación con Moisés; según Müller, a través del rollo y la acción profética de Juldá se la vincula con la figura de Moisés (MÜLLER, 2008, p. 4). El texto de 2 R 22,11-20 tiene el escenario del tiempo del rey Josías (641-609 a. C.) en el reino del Sur. Josías es conocido por su papel en la reforma del culto (REITERER, 2012, p. 438; PIKAZA, 2015, p. 667), como ser la restauración

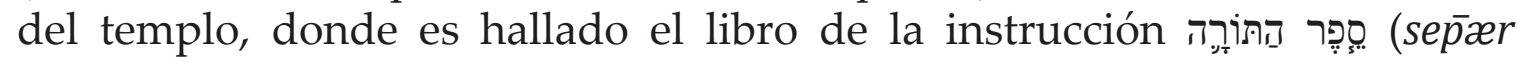

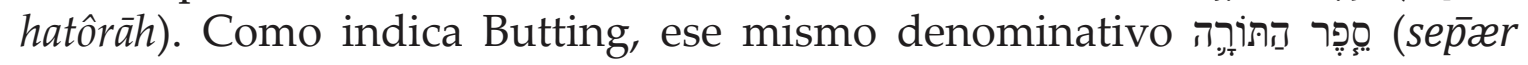


hatôrāh) se encuentra también en el Deuteronomio (Dt 28,61; 29,20; 30,10; 31,26) (BUTTING, 2001, p. 127). Este hallazgo crea consternación en el rey tanto así que se rasga sus vestiduras, símbolo de penitencia (2 R 22,5.8-11). Cabe destacar que la reforma de Josías está también relacionada con actos de violencia e intolerancia en nombre de Dios (MONTEIRO DE MATOS, 2020, p. 60). Según Weems, Juldá pudo haber vivido en la misma época de los profetas Sofonías, Nahúm y Habacuc (WEEMS, 2003, p. 329). El relato de 2 R 22 se lo puede datar no antes del exilio, esto teniendo en cuenta el lenguaje y la forma deuteronomista del texto (FISCHER, 2002, p. 170).

\section{Yhwh habla por medio de la palabra de Juldá}

Una de las características de comunicación o diálogo de YHWH con su pueblo es el del profetismo. YHWH llama tanto a varones como a mujeres para ese servicio. "[F]emale prophets were not unheard of. Despite the many speculations about her gender, Huldah stood in a long tradition of women who throughout the Former Prophets showed themselves to be quick-witted and wise, discerning and able to invoke Yhwh's words for circumstances when the time called for them to do so" (WEEMS, 2003, p. 330-331). A razón de ello es importante conocer más a fondo el servicio que prestaron.

Desde una perspectiva bíblica, el hecho de encontrarse con Dios o ver su gloria era considerado algo peligroso, que podía costar incluso la vida (Gn 32,31; Ex 33,20). Las personas escogidas por YHWH tenían el papel de ser mediadoras en cuanto transmitían la Palabra divina, pero a la vez podían ser mediadoras del pueblo delante de Dios. En uno de los textos del Éxodo se puede leer como Moisés aplaca la irá de YHWH en contra de su pueblo, quien le había sido infiel con el becerro de oro (Ex 32,1-14). En esta perícopa se puede leer con qué habilidad Moisés logra ese su objetivo, argumentando que la ira de $\mathrm{YHWH}$ sería contra productiva a los ojos de los egipcios: "11 «¿Por qué, oh Yahvé, ha de encenderse tu ira contra tu pueblo, el que tú sacaste del país de Egipto con gran poder y mano fuerte? 12 ¿Por qué han de decir los egipcios que los sacaste con mala intención, para matarlos en las montañas y exterminarlos de la superficie de la tierra? Abandona el ardor de tu cólera y arrepiéntete de la amenaza contra tu pueblo $[\ldots]\rangle^{\prime \prime 1}$ (Ex 32,11-12).

Las y los profetas a parte de mediadores eran personas por medio de las cuales se consultaba a YHWH (DE VAUX, 1992, p. 458; IRIARTE, M., 1992, p. 46). En este punto Juldá juega un papel importante en el relato sobre

\footnotetext{
${ }^{1}$ Para las citas bíblicas se utiliza la Biblia de Jerusalén.
} 


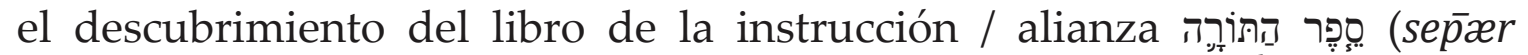
hatôrāh). "[L]a expresión 'libro de la alianza' aparece en Éxodo (24,7), pero no en Deuteronomio. Eso significa que los capítulos de 2 Re 22-23 fueron revisados y ampliados durante los períodos babilónico y persa para transformar el informe sobre la reforma en una historia sobre los orígenes

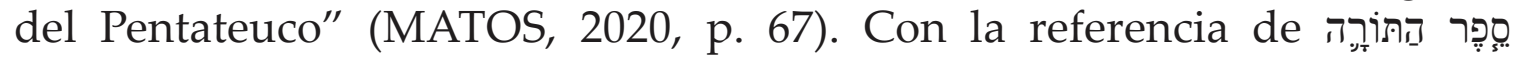
(sep̄ær hatôrāh) se determina el marco del texto que es la alianza, es decir se puntualiza el aspecto central teológico. Con este dato se da a entender que no se trata de un texto cualquiera. Esto subraya el significado del servicio de la interpretación que prestará la persona a quien se consulte. Por lo tanto "[e]sta profetisa pasa a un primer plano como autoridad religiosa principal en un momento de intenso reavivamiento espiritual (2 R 22:14)" (DAVIDSON, 2004, p. 112).

Llama la atención que ni el sacerdote Jilquias, ni el escriba Safán y tampoco el ministro Asayas podían prestar el servicio de la interpretación del texto encontrado, solamente Juldá. "But by limiting his description of her to her name, her status as wife of the king's valet, and her dwelling in a section of Jerusalem beyond the borders of the royal guild of scribal activity, the narrator contrasts her marginal status to that of the elite policy-makers who seek her out" (WEEMS, 2003, p. 323). De esa manera subraya el texto que la Palabra de YHWH es independiente de toda institución, jerarquía o poder. Cabe destacar que en el libro de Jeremías se hace referencia al servicio relacionado con el sacerdote, con la persona sabia y con la que ejerce la profecía: "Vamos a tramar algo contra Jeremías, porque no va a faltarle la ley al sacerdote, el consejo al sabio, ni al profeta la palabra. Vamos a calumniarle y no hagamos caso de sus palabras" (Jr 18,18) (CAERO BUSTILLOS, 2010, p. 37-54). En el caso de nuestra perícopa queda claro que no se requiere solamente un consejo en relación con el texto encontrado, sino una verificación del mismo en su contenido.

La diferenciación en la diversidad de servicios es importante para no monopolizar o centralizarlos en uno solo. Al respecto escribe Butting: "Por esa razón, los que tienen la potestad de la palabra en la historia de Israel, no tienen nada que decir en la actualización de la tradición histórica escrita" (BUTTING, 2001, p. 139, traducción propia del alemán). A parte de ello indica la misma autora, que la profetisa Juldá representa la no disponibilidad de Dios a pesar de la Torá escrita, a la vez señala la crisis y la innovación de las estructuras sociales existentes, lo cual implica que el libro encontrado sea interpretado desde el ámbito profético (BUTTING, 2001, 139). No son los escritos o las instituciones que aseguran la presencia de YHWH en medio de su pueblo, sino la interacción de YHWH con su pueblo por medio de la palabra profética.

La autoridad profética con la que Juldá se dirige a quienes le buscan, se puede apreciar en las primeras palabras que ella expresa: "Así habla YHWH, 


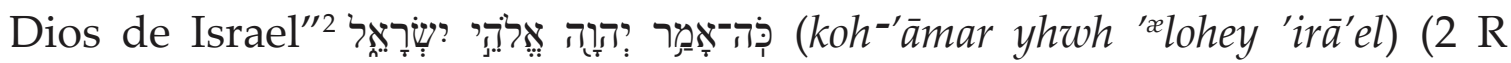
$22,15)$, es decir con una fórmula propia del profetismo. El texto es directo. La mano redactora parece no estar interesada en diálogos innecesarios, al contrario, se enfoca en la finalidad de escuchar la Palabra de $\mathrm{YHWH}$, en este caso por medio de la voz de la profetisa Juldá.

En la versión del libro de Reyes desemboca la profecía de Juldá en la reforma del culto (2 R 22-23) (MÜLLER, 2008, p. 2) y la política (WEEMS, 2003, p. 322), mientras que en la versión del libro de Crónicas la reforma es previa (2 Cr 34,8s.) (MÜLLER, 2008, p. 2). Si bien el texto, como otros textos de la Biblia, está en debate en cuanto a su historicidad (MÜLLER, 2008 , p. 3), cabe destacar - en este caso - el mensaje teológico que transporta. De todas maneras, se puede situar el texto de Juldá, según Müller, en el exilio tanto por el anuncio de la caída de Jerusalén como por el lenguaje deuteronómico (MÜLLER, 2008, p. 3).

La perícopa de 2 R 22,11-20 presenta un escenario donde interactúan personajes del ámbito político, como ser el rey y su ministro y del ámbito religioso, representados por los sacerdotes y una profetisa. Es un espacio donde cada uno ejerce su servicio en función de una correcta actitud frente a una situación concreta que es el descubrimiento del mensaje del libro de la instrucción / Torá (MÜLLER, 2008, p. 3). Cabe destacar que el texto no presenta como algo extraordinario la participación de una mujer en el rol de transmitir la palabra de YHWH. Tampoco se pone en tela de juicio lo que ella profetiza (MÜLLER, 2008, p. 3). La mano redactora hila el texto con tal precisión, que desde el inicio queda clara la autoridad que ejercía Juldá por medio de las palabras del rey Josías: "«Id a consultar a Yahvé por mí y por el pueblo y por toda Judá [...]»" (2 R 22,15). Por lo tanto, se puede indicar: "She is the first figure in Scripture, male or female, whose contribution to biblical history centered on verifying a written document as sacred and holy writ" (WEEMS, 2003, p. 321). Butting señala que por medio de la proclamación de Juldá se transforma el libro de las instrucciones $(22,8.11)$ en el libro de la alianza $(23,2.21)$ (BUTTING, 2007, p. 161). De esa manera "se acentúa la necesaria conexión de la Torá y la profecía y con ello se desarrolla el significado del canon profético" (WEEMS, 2003, p. 323, traducción propia).

\section{El rol de las mujeres en los textos bíblicos}

Tanto en el Primer como en el Segundo Testamento, según CalduchBenages, "aparecen 175 mujeres con nombre propio. Por supuesto, hay muchas mujeres y grupos de mujeres anónimos (p. ej., las 400 vírgenes

${ }^{2}$ Traducción propia. 
de Galaad en Jue 21,12). Incluyendo estas figuras anónimas -no contamos las referencias genéricas a la mujer o a grupos indefinidos sin número-, la cifra llega hasta 674" (CALDUCH-BENAGES, 2008, p. 11). Teniendo en cuenta esos datos, existe un material amplio que nos ofrece la Biblia para una reflexión profunda sobre el destacado rol de las mujeres en la historia de salvación del pueblo de Dios.

Si bien el mundo bíblico tiene un escenario con un acento androcéntrico, "[w]e know that speechmaking was not a male activity alone. The Queen of Sheba, the wise women of Tekoa and Abel-Beth-Maacah, and Abigail, among others, also spoke at critical junctures in the history of Israel to confirm Yhwh's will to a divinely chosen leader and to call Israel to renewed obedience" (WEEMS, 2003, p. 331). Tal es el caso de la profetisa Juldá que presta un servicio relevante en un momento de un proceso de reforma delicado. Pese al rol significativo que tienen estas mujeres, hay una tendencia de darles un rol secundario al lado del rol principal de un varón, como por ejemplo Débora, Yael (Jc 4) o la mujer sabia de Tecoa (2 S 14) entre otras (WEEMS, 2003, p. 332). Esa forma de recensión que se hace sobre estas mujeres refleja el escenario histórico androcéntrico de esa época, tanto así que su sombra se la percibe hasta nuestros días. A pesar de ello no se calla en los textos bíblicos el servicio de la profecía que ejercen las mujeres.

A lado de Juldá se mencionan también como profetisas del pre-exilio a Mirian (Ex 15), Débora (Jc 4) y como profetisa del pos-exilio a Noadía (Neh 6). "While Huldah's professional identity in Scripture is that of prophet, she functions in 2 Kings 22 more in the tradition of her Deuteronomistic female predecessors, the wise women of 2 Samuel 14 and 20 who also spoke authoritatively and persuasively to royal male figures who crossed their paths" (WEEMS, 2003, p. 333). En el caso de esas tres profetizas no se hace mención que ellas hubieran tenido hijos o hijas. "Esas mujeres no derivan su prestigio por medio de la maternidad, sino por el cargo que ejercen" (FISCHER, 2002, p. 162-163). Aspecto que en esos escenarios no era común, tal es el caso de Lea y Raquel (Gn 29,31-30,25), donde la maternidad tiene un lugar importante en el texto.

La recensión que recibió Juldá como profetisa es los escritos de los Padres de la Iglesia (Hipólito, Eusebio, Jerónimo, Lucifer de Cagliari, Afrates, Agustín, Teodoreto) (SIQUANS, 2011, p. 245-249), según la autora Siquans, a diferencia con Mirian y Débora es poca. En esos textos se hace más referencia a los personajes masculinos, como ser el rey Josías o la relación de Juldá con su contemporáneo Jeremías. Según la autora eso no resta valor al personaje de Juldá en esos escritos (SIQUANS, 2011, p. 245). "Pero no se reflexiona más sobre su persona. Tampoco el texto bíblico lo sugiere, que es breve cuando se refiere a Juldá. Juldá como Débora no es la personaje principal de la narración, sino se la menciona casi de pasada. 
No obstante, ella gana autoridad como profetisa, cuyas palabras después de todo han sido transmitidas textualmente" (SIQUANS, 2011, p. 253, traducción propia).

El rol y la fuerza de las mujeres en los textos bíblicos se refleja en el impacto de su presencia en la historia de salvación, que sobresalen incluso en textos que tienen un escenario histórico androcéntrico. Lo que nos llegó hasta nuestras manos son las formas y maneras como se las recensionó a estas mujeres.

\section{Una voz profetica (2 Rs 22,11-20)}

Según Butting el discurso de Juldá se divide en dos partes: I 22,15-17 y II 22,18-20 (BUTTING, 2001, p. 142). Si se tiene en cuenta el entorno profético de Juldá está presente la figura de Jeremías. En los estudios sobre esta profetiza surge la pregunta, por qué ha sido consultada ella, si se podía haber consultado también a Jeremías. El la tradición rabínica es considerada Juldá junto a Miriam, Débora, Abigail y Ester como las siete profetizas judías (bMeg ${ }^{3}$ 14a) (GROHMANN, 2019, p. 22; CALDUCHBENAGES, 2008, p. 16). A la pregunta anteriormente hecha responde la tradición judía indicando que Juldá era pariente de Jeremías y que éste no se lo reprochó (bMeg 14b) (GROHMANN, 2019, p. 22). Otra respuesta por la que Josías la eligió a ella y no a Jeremías es aquella que indica que las mujeres son consideradas más misericordiosas o porque Jeremías no se encontraba en el lugar (GROHMANN, 2019, p. 22). "Los rabinos ven por lo tanto el efecto simultaneo de Juldá y Jeremías y buscan aclarar, por qué el rey Josías no manda a su delegación a Jeremías, sino a Juldá - un hecho, que en el texto bíblico se lo da por supuesto" (GROHMANN, 2019, p. 22, traducción propia).

Si bien la profetisa Juldá no parece vivir en el centro político y religioso de la ciudad, "Huldah may very well have been a legal expert with northern ties, a descendant of northern prophetic circles in particular, head of a circle of scribes living in the Second Quarter who had devoted themselves to preserving their northern Mosaic heritage. All of this may just explain why Huldah (and not, say, Jeremiah or Zephaniah) was consulted when the scroll containing Mosaic legislation was happened upon during temple repairs" (WEEMS, 2003, p. 334).

Ella no solamente verifica la autenticad de un documento, sino que hace ejercicio de su vocación profética indicando a lo que se tiene que atener

${ }^{3}$ Talmud babilónico Megilla. 
Judá (WEEMS, 2003, p. 325). "It is her reputation as a prophet with expertise in legislation that brings her to the attention of Josiah and her readers. She filled a very real void in the cataclysmic events of the seventh century. Here was a prophet, a spokesperson in the Deuteronomistic tradition, who could see what no one else could see at the time: Time was running out for Judah" (WEEMS, 2003, p. 329). Su acción profética será confirmada cuando el reino de Judá cae ante imperio de Babilonia (2 R 24-25) (CALDUCH-BENAGES, 2008, p. 19).

Wacker escribe que no se puede definir si era una profetisa del templo o una profetisa "libre". De todas maneras, ella utiliza el mismo lenguaje que su contemporáneo Jeremías, ambos se expresan de la misma manera (WACKER, 1988, p. 93). A diferencia de Wacker indica Fischer que Juldá no era una profetisa en el palacio y que estaba acostumbrada a tratar con autoridades de estado (FISCHER, 2002, p. 164). Esto por su forma de dirigirse a la delegación que viene a verla a su casa, y por no hacer uso de un lenguaje diplomático, tampoco al hacer referencia al rey, como lo haría una súbdita del rey, algo que también lo hacían sus colegas contemporáneos (FISCHER, 2002, p. 164). Por esas formas de dialogar se cristaliza que en el centro de la narración no se trata de una determinada persona o autoridad, sino de la Palabra de YHWH (FISCHER, 2002, p. 164). La forma en la que Juldá se refiere al rey es un argumento para Fischer para no localizarla en el círculo de la profecía de la corte (FISCHER, 2002, p. 164).

\section{Plena participación un desafío en el camino sinodal}

En nuestro continente latinoamericano y caribeño se emprendió el camino de la Asamblea Eclesial, donde uno de los temas que desafía a la Iglesia de hoy es el "de la plena participación de las mujeres en la sociedad y en la Iglesia" (CELAM, 2021, p.13).

El tema de la plena participación de la mujer a nivel social y eclesial está desde mi punto de vista relacionado con la plena participación en la vida. Esto implica una visión íntegra de la persona. Una persona, para poder participar plenamente en cualquier ámbito, necesita gozar de Este término hebreo implica el bienestar de la persona a nivel corporal, social, espiritual, económico y psicológico. . [...] paz, salud, bienestar, prosperidad material y espiritual del individuo y de la sociedad; y en este contexto las buenas relaciones entre personas, familias, clanes y pueblos, así como dentro del matrimonio y en la relación de la persona con Dios" (ERNST, 2012, p. 606. Más sobre el tema שָלוֹ šālôm: STENDEBACH, 1995, p. 12-46). Todos esos aspectos que implica Š šalôm tiene que ver con la plena participación en la vida. 
Por lo tanto, es importante hacerse la siguiente pregunta: ¿Cuáles son las actuales realidades sociales por las que atraviesan mujeres en nuestro continente? Una de esas realidades que se hizo más latente en la pandemia es la violencia familiar. Nuestras sociedades sufren heridas de violencia sobre todo contra mujeres, niñas y niños. En Bolivia reportó el Instituto de Investigaciones Forenses del 1 de enero al 11 de julio de este año 61 casos de feminicidios y 19 casos de infanticidios (LOS TIEMPOS, 2021). A parte de esas violencias físicas están aquellas heridas que no son visibles a los ojos biológicos y que quedan estigmatizadas por el silencio.

Para poder reflexionar sobre el papel de la mujer en la teología es importante develar el espacio en la que ella hace teología. Con espacio me refiero no solamente al ámbito geográfico, sino también a las circunstancias que la rodean. Los frutos teológicos sembrados por mujeres a lo largo de la historia siguen siendo cosechados por diversas generaciones. Esos frutos tienen una historia y un camino recorrido concreto.

Para un camino sinodal sería importante re-visitar la historia teológica de aquellas mujeres que dieron su aporte teológico y siguen dando a la sociedad y a la Iglesia. Lo cual implicaría preguntar: ¿Cuáles han sido las circunstancias por las que ellas atravesaron para hacer teología? ¿Cuáles han sido los obstáculos que tuvieron que superar para seguir adelante? ¿Quiénes estuvieron a su lado apoyándolas en ese camino? ¿Qué papel jugaron las estructuras sociales y eclesiales en su labor teológica? y sobre todo ¿Cuáles han sido sus fuentes de inspiración y perseverancia?

Para poder comprender y profundizar esos frutos teológicos, sería importante conocer el marco de la teología que ellas nos heredan. Ese conocimiento invitaría a reflexionar sobre qué caminos sinodales se quieren emprender en el futuro.

En este momento, el camino de la Asamblea Eclesial se encuentra en la

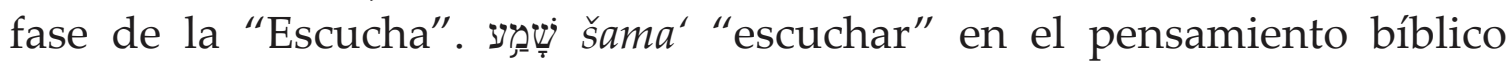
implica entender y comprender aquello que se me comunica. En el Antiguo Testamento, como vimos en la primera parte de este artículo, tenemos a las profetisas y a los profetas, quienes transmiten la Palabra de $\mathrm{YHWH}$ para ser escuchada. Estas personas son un medio por quienes YHWH entra en diálogo con su pueblo (RÜTERSWÖRDEN, 1995, p. 260). El órgano del oído se lo utiliza también para otros órganos del cuerpo como ser el corazón, tal es el caso de Salomón que pide a YHWH un corazón que escucha (1 R 3,9) (RÜTERSWÖRDEN, 1995, p. 269; SCHROER; STAUBLI, 2005, p. 100).

El papel de la mujer en la teología tiene implicaciones proféticas. Esa palabra tiene sus propios rasgos y características, que mayormente quedaron ocultos a primera vista. No se trata solamente de escuchar una voz fémina en la teología, sino de tener un conocimiento de las circunstancias en las 
que surgen esas voces. Es decir, tener un conocimiento histórico de lo que apoya esa teología.

La Palabra de Dios ha sido y sigue siendo encomendada tanto a mujeres como a varones. Una sinodalidad vivida reconoce plenamente que cada persona tiene derecho en la participación plena de la vida. La voz profética no tiene su fundamento en el reconocimiento del ejercicio de un determinado cargo, sino en $\mathrm{YHWH}$, el Dios de la Vida. Cada persona tiene el derecho de participar plenamente en la revelación de Dios por medio de su Palabra entregada a su creación y por su creación.

\section{Conclusión}

Juldá que en hebreo también puede significar "tiempo de vida" sobresale en 2 R 22,11-20 por su presencia y autoridad profética. Tal vez el significado de "tiempo de vida" haga alusión al tiempo de su vida profética, es decir ella tuvo la posibilidad de poder vivir plenamente ese su servicio. En el caso de Juldá sobresale el aspecto de la consulta que se hace a YHWH por medio de su persona. Los representantes políticos y religiosos reconocen dicha autoridad, prevaleciendo de esta manera el servicio que ella presta como portavoz de YHWH (2 R 22,15). Cabe destacar que a Juldá como a Miriam y Débora no se las define por su maternidad, sino por su acción profética. A pesar de que mujeres como Juldá o Débora, entre otras, tuvieron un rol importante, escenarios androcéntricos les designaron un rol secundario.

Los escenarios en los que se hace teología requieren ser analizados, porque son parte fundante del quehacer teológico de las mujeres. Un camino sinodal implica también re-visitar la historia para promover actitudes sociales y eclesiales que fortalezcan la participación plena de mujeres en esos ámbitos, porque una participación plena es el derecho que tiene cada ser humano de poder expresar su experiencia de Dios en la diversidad de servicios y ministerios.

\section{Referencias}

BIBLIA DE JERUSALÉN. Nueva Edición totalmente revisada. UBIETA LÓPEZ J.A. (Dir.) 4. ed. Bilbao: Desclée De Brouwer, 2009.

BIBLIA HEBRAICA STUTTGARTENSIA. ELLIGER K.; RUDOLPH W. (Dir.) 5. ed. Stuttgart: Deutsche Bibelgesellschaft, 1997.

BUTTING, K. Prophetinnen gefragt. Die Bedeutung der Prophetinnen im Kanon aus Tora und Prophetie. Knesebeck: Erev-Rav, 2001. 
BUTTING, K. Hulda - Eine Prophetin im Zeitalter des Kanons. In: KEUCHEN, M.; KUHLMANN, H.; SCHROETER-WITTKE, H. (Ed.). Die besten Nebenrollen. 50 Porträts biblischer Randfiguren. 2. ed. Leipzig: Evangelische Verlagsanstalt, 2007, p. 160-164.

CAERO BUSTILLOS, B.C. Pues no se pierde la Torá del sacerdote, el consejo del sabio, la palabra del profeta (Jr 18,18). Yachay, n. 52, p. 37-54. 2010.

CALDUCH-BENAGES, N. Las mujeres bíblicas: rastreando sus huellas, Scripta Fulgentina, Murcia, v. 18, n. 35-36, p. 7-22, 2008.

CONFERENCIA EPISCOPAL LATINO AMERICANA (CELAM). Asamblea Eclesial de América Latina y El Caribe. Disponible en: <https://asambleaeclesial.lat/ wp-content/uploads/2021/05/Gu\%C3\%ADa-Asamblea-Eclesial-Popular-CELAMRV_compressed_ES.pdf>. Acceso en: 8 ago. 2021.

DAVIDSON, J.A. Las mujeres en la Escritura: Estudios y Evaluación. In: TORREBLANCA, J.; DE VYHMEISTER, N.W. (Ed.). Mujer y Ministerio. Perspectivas bíblicas e históricas. Berrien Springs: Andrews University Press, 2004, p. 102-124.

DE VAUX, R. Instituciones del Antiguo Testamento. 4. ed. Barcelona: Herder, 1992.

ERNST, M. Paz. In: KOGLER, F.; EGGER-WENZEL, R.; ERNST, M. (Ed.). Diccionario de la Biblia. Bilbao; Santander: Mensajero; Sal Terrae, 2012, p. 606.

FISCHER, I. Gotteskünderinnen. Zu einer geschlechterfairen Deutung des Phänomens der Prophetie und der Prophetinnen in der Hebräischen Bibel. Stuttgart: Kohlhammer, 2002.

GRADL, F. Juldá. In: KOGLER, F.; EGGER-WENZEL, R.; ERNST, M. (Dir.). Diccionario de la Biblia. Bilbao; Santander: Mensajero; Sal Terrae, 2012, p. 457.

GROHMANN, M. Deuteronomistische und rabbinische Autorisierungsstrategien der Tora. In: HEIL, U.; KLEIN, A.; SCHELLENBERG, A. (Ed.). Autor und Autorität. Historische, systematische und praktische Perspektiven. Göttingen: V\&R unipress $\mathrm{GmbH}, 2019$, p. 15-36.

IRIARTE, M.E. Mujer y ministerio: Antiguo Testamento, Diakonía, Nicaragua, n. 63, p. 43-58, 1992.

LOS TIEMPOS, Fiscalía reporta 61 feminicidios y 19 infanticidios en lo que va de 2021. 2021. Disponible en: <https://www.lostiempos.com/actualidad/seguridad/20210712/fiscalia-reporta-61-feminicidios-19-infanticidios-que-va-2021>. Acceso en: 8 ago. 2021.

MATOS, S'.H. MONTEIRO DE. La reforma de Josías y la legitimación de la violencia. Consideraciones arqueológico-históricas, exegéticas y hermenéuticas en la perspectiva de género, a partir de 2 Re 23,1-25, Revista Bíblica, v. 82, n. 1-2, p. 59-77. 2020.

MÜLLER, M. Hulda. Das wissenschaftliche Bibellexikon im Internet, 2008. Disponible en: <https://www.bibelwissenschaft.de/fileadmin/buh_bibelmodul/media/wibi/pdf/ Hulda_2018-09-20_06_20.pdf>. Acceso en: 7 jul. 2021.

PIKAZA, X. Gran Diccionario de la Biblia. 2. ed. Villatuerta (Navarra): Verbo Divino, 2015.

RAMOS, José Augusto M. A Mulher na Bíblia. In: CURADO SANTOS, Maria Clara (Org.). A mulher na história. Actas dos coloquios sobre a temática da mulher (1999-2000). Câmara Municipal Da Moita, 2001, p. 45-52. 
REITERER, F.V. Josías. In: KOGLER, F.; EGGER-WENZEL, R.; ERNST, M. (Dir.). Diccionario de la Biblia. Bilbao; Santander: Mensajero; Sal Terrae, 2012, p. 438.

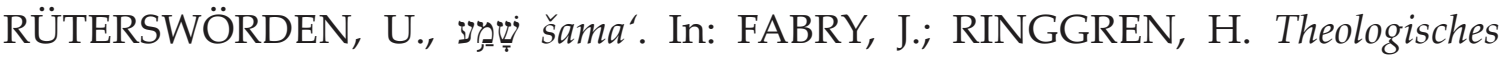
Wörterbuch zum Alten Testament. Stuttgart; Berlin; Köln: Kohlhammer, 1995, v. 8. p. 255-279.

SCHROER, S.; STAUBLI, T. Die Körpersymbolik der Bibel. 2. ed. Darmstadt: Wissenschaftliche Buchgesellschaft, 2005.

SIQUANS, A. Die alttestamentlichen Prophetinnen in der patristischen Rezeption. Texte - Kontexte - Hermeneutik. Freiburg; Basel; Wien; Barcelona; Rom; New York: Herder, 2011.

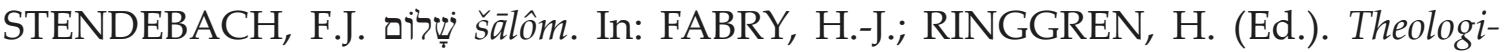
sches Wörterbuch zum Alten Testament. Stuttgart; Berlin; Köln: Kohlhammer, 1995. v. 8 , p. $12-46$.

WACKER, M.-T. 2. Könige 22,8.9a10b.11-20. Hulda - Prophetin vor dem Ende. Vorletzter Sonntag im Kirchenjahr; Buß- und Bettag. In: Feministisch gelesen / 1 / 32 ausgewählte Bibeltexte Für Gruppen, Gemeinden u, Gottesdienste. Stuttgart: Kreuz Verlag, 1988, p. 91-99.

WEEMS, R.J. Huldah, the Prophet: Readding a (Deuteronomistic) Woman's Identity. In: STRAWN, B.A.; BOWEN, N.R. (Ed.). A God so Near. Essays on Old Testament Theology in Honor of Patrick D. Miller. Penn State University Press, 2003. p. 321-339. E-book.

Artículo sometido en 16.08.2021 y aprovado en 30.11.2021.

Bernardeth Carmen Caero Bustillos Doctora en Teología Bíblica por la Universidad de Salzburgo (Austria). Docente y Directora del Segundo y Tercer Ciclo de la Facultad de Teología "San Pablo" (FTSP) en Cochabamba (Bolivia). Coeditora de la Revista Internacional de Teología Concilium. Miembro de ISDCL y de ABA. Áreas de investigación: Teología Bíblica, Teología Interdisciplinar, Teología India cristiana, Hebreo Bíblico.

Orcid.org/0000-0001-8677-4813. E-mail: bcaero@ucb.edu.bo

Dirección: Casilla 1674, Cochabamba - Bolivia. 